\title{
Isolated pulmonary metastases in patients with cervical cancer and the factors affecting survival after recurrence
}

\author{
Varol Gülseren', Mustafa Kocaer², Özgü Güngördükk ${ }^{3}$ İsa Aykut Özdemir ${ }^{4}$, Ceren Gölbaşı², \\ Adnan Budak ${ }^{2}$, İlker Çakır ${ }^{2}$, Mehmet Gökçüi ${ }^{2}$, Muzaffer Sancı ${ }^{2}$, Kemal Güngördüik ${ }^{3}$ \\ ${ }^{1}$ Mersin State Hospital, Department of Obstetrics and Gynecology, Mersin, Turkey \\ ${ }^{2}$ Tepecik Education and Research Hospital, Department of Obstetrics and Gynecology, İzmir, Turkey \\ ${ }^{3}$ Muğla Sıtkı Koçman University, Department of Obstetrics and Gynecology, Muğla, Turkey \\ ${ }^{4}$ Sadi Konuk Education and Research Hospital, Department of Gynecological Oncology, Istanbul, Turkey
}

\begin{abstract}
Objectives: The aim of this study was to assess the treatment options and survival of uterine cervical cancer (UCC) patients who develop isolated pulmonary metastases (IPM) and to establish risk factors for IPM.

Material and Methods: Data from patients diagnosed with UCC between June 1991 and January 2017 at the Gynecological Oncology Department, Tepecik Training and Research Hospital, were investigated. In total, 43 cases with IPM were evaluated retrospectively. Additionally, 172 control patients diagnosed with UCC without recurrence were matched according to the International Federation of Gynecology and Obstetrics (FIGO) 2009 stage when the tumor was diagnosed. They were selected using a dependent random sampling method.

Results: Of the 890 patients with UCC, 43 (4.8\%) had IPM. The presence of lymphovascular space invasion (LVSI) and a mid-corpuscular volume $(\mathrm{MCV})<80 \mathrm{fL}$ were statistically significant prognostic factors for IPM development in UCC patients according to univariate regression analyses, and the presence of $\mathrm{LVSI}$, a hemoglobin level $<12 \mathrm{~g} / \mathrm{dL}$, and an $\mathrm{MCV}<80 \mathrm{fL}$ were statistically significant according to the multivariate regression analyses. We were unable to assess the role of lymph node status (involvement or reactive) as a prognostic factor in the development of IPM, because only seven patients (16.2\%) in the case group underwent lymph node dissection.

Conclusions: IPM typically develops within the first 3 years after the diagnosis of UCC, and survival is generally poor. An $M C V<80 \mathrm{fL}$ and the presence of LVSI are significant risk factors for IPM development.
\end{abstract}

Key words: uterine cervical cancer; isolated pulmonary metastases

Ginekologia Polska 2018; 89, 11: 593-598

\section{INTRODUCTION}

Uterine cervical cancer (UCC) is the third-most common malignancy among gynecological cancers [1]. As a result of screening programs, the detection of early stage UCC has been gradually increasing. Although metastasis at the time of initial diagnosis of UCC is rare, $15-61 \%$ of patients eventually develop metastases within 28 years [2].

Hematogenous spread of UCC is rare; lung (36.3\%), bone (16.3\%), liver, and brain metastases are most common [3]. The incidence of isolated pulmonary metastasis (IPM) in UCC patients is $3.1-9.9 \%$ [3-5]. The primary cancer types that most fre- quently cause IPM are breast, larynx, prostate, thyroid, bladder, stomach, and pancreatic cancers, in that order [5,6]. Among the types of gynecological malignancies, sarcomas have a higher incidence of IPM than do epithelial cancers [6]. IPM is asymptomatic and can be recognized by follow-up imaging methods or by symptoms such as cough, chest pain, hemoptysis, respiratory distress, and drowsiness, depending on location and size.

The mean survival of patients with metastatic UCC is 8-13 months, and the 5-year survival rate is 7.5-16.5\% [3]. Conventional treatments such as surgery, chemotherapy (CT), and radiotherapy (RT) are used in early and locally 
advanced UCC patients; however, there is no standard treatment for patients with UCC with IPM. The aim of this study was to assess the treatment options and survival of UCC patients who develop IPM and to establish risk factors for IPM.

\section{PATIENTS AND METHODS}

Data from patients diagnosed with UCC between June 1991 and January 2017 at the Gynecological Oncology Department, Tepecik Training and Research Hospital, were investigated. In total, 43 cases with IPM were evaluated retrospectively. Additionally, 172 control patients diagnosed with UCC without recurrence were matched according to the International Federation of Gynecology and Obstetrics (FIGO) 2009 stage when the tumor was diagnosed. They were selected using a dependent random sampling method. This study was approved by the institutional ethics committee and was conducted in accordance with the ethical standards of the Declaration of Helsinki.

All surgical specimens were examined and interpreted by gynecological pathologists. Architectural grading was defined by standard FIGO criteria. All tumors were staged according to the 2009 FIGO staging system. In patients treated before 2009, stage was determined retrospectively based on surgical and pathological assessments.

Blood counts were measured at the time of the initial UCC diagnosis. Staging was performed according to the FIGO 2009 clinical staging system by examination under general anesthesia, and patients were evaluated using imaging modalities. Women completed follow-up evaluations every 3 months for the first 2 years, every 6 months for the next 3 years, and annually thereafter. Computed tomography or magnetic resonance imaging was performed annually.

Clinical and pathologic data were obtained from patient files and pathology reports. The diagnosis of pulmonary metastasis was confirmed by histopathology or imaging. Patient age, menopausal status, disease-free survival (DFS), overall survival (OS), type of primary treatment (such as surgery, CT, $\mathrm{RT}$, or chemoradiotherapy (CRT), recurrence, and treatment of recurrence were also investigated. Tumor size, lymphovascular space invasion (LVSI), number of pelvic and para-aortic lymph nodes, lymph node involvement, and size of vaginal and lymph node metastases were analyzed in accordance with the pathology reports. Patients with IPM were investigated in terms of treatment options (e.g., CT, RT, or CRT) and survival.

DFS was defined as the time from the date of primary surgery to detection of recurrence or the most recent observation. OS was defined as the time from the date of primary surgery to death or the most recent observation. Post-metastasis survival was defined as the time between the date of recurrence and the time of the last control clinic visit or death. Survival analysis was performed using the Kaplan-Meier method, and the results were compared by log-rank test. Logistic regression analysis was used to define the risk factors for IPM. The results are presented as odds ratios (OR) and $95 \%$ confidence interval (Cl) Cls. Cox regression analysis was used to determine the factors affecting survival, with the results presented as hazard ratios. The Chi-square test and Student's $t$-test for unpaired data were used for statistical analysis. All statistical analyses were performed using MedCalc software (version 14.0 for Windows; MedCalc Software bvba, Ostend, Belgium; https:// www.medcalc.org; 2016). A P-value $<0.05$ was considered to indicate statistical significance.

\section{RESULTS}

Of the 890 patients with UCC, 43 (4.8\%) had IPM. The median detection time of IPM was 24.0 months (range 0-96 months) after UCC diagnosis. The demographic characteristics of the patients in the IPM and control groups are shown in Table 1 and the primary therapies for both groups in Table 2. Of the IPMs, $18.6 \%$ were solitary, and $81.4 \%$ were multiple lesions. A median of 3 (range 2-5) lesions were detected in 35 patients with multiple lesions. Within the IPM group, $2.9 \%$ (9 of 304) patients were stage IB, $1.6 \%$ (1 of 59) stage IIA, $6.0 \%$ (19 of 312) stage IIB, 3.4\% (2 of 58) stage IIIA, $10.0 \%$ (6 of 60 ) stage IIIB, and $50.0 \%$ (6 of 12 ) stage IVB.

For IPM treatment, 35 (81.4\%) patients received CT only, 4 (9.3\%) received surgery plus $\mathrm{CT}, 3(7.0 \%)$ received $\mathrm{RT}$, and $1(2.3 \%)$ received palliative support treatment. According to

\begin{tabular}{|c|c|c|c|}
\hline & Cases (43) & Controls (172) & $\mathbf{P}$ \\
\hline Age, mean $\pm S D$, years & $58.9 \pm 10.8$ & $54.3 \pm 10.5$ & 0.012 \\
\hline Tumor size, mean $\pm \mathrm{SD}, \mathrm{cm}$ & $4.5 \pm 1.3$ & $4.1 \pm 1.5$ & 0.145 \\
\hline Hemoglobin, mean $\pm \mathrm{SD}, \mathrm{g} / \mathrm{dL}$ & $11.8 \pm 2.0$ & $11.6 \pm 1.8$ & 0.560 \\
\hline$M C V$, mean $\pm S D$ & $79 \pm 9.8$ & $83.2 \pm 7.3$ & 0.011 \\
\hline $\mathrm{DFS}$, mean $\pm \mathrm{SD}$, months & $29.5 \pm 26.0$ & - & - \\
\hline OS, mean $\pm S D$, months & $55.0 \pm 53.2$ & $90.8 \pm 57.3$ & 0.001 \\
\hline Postmenopausal status, n [\%] & $34(79.1)$ & $116(67.4)$ & 0.095 \\
\hline $\begin{array}{l}\text { Stage, n [\%] } \\
\text { IB1 } \\
\text { IB2 } \\
\text { IIA } \\
\text { IIB } \\
\text { IIIA } \\
\text { IIIB } \\
\text { IVB }\end{array}$ & $\begin{array}{l}2(4.7) \\
7(16.3) \\
1(2.3) \\
19(44.2) \\
2(4.7) \\
6(14.0) \\
6(14.0)\end{array}$ & $\begin{array}{l}8(4.7) \\
28(16.3) \\
4(2.3) \\
76(44.2) \\
8(4.7) \\
48(27.9) \\
0\end{array}$ & \\
\hline $\begin{array}{l}\text { Histological type, } \mathbf{n}[\%] \\
\text { Squamous cell carcinoma } \\
\text { Adenocarcinoma } \\
\text { Adenosquamous cell carcinoma }\end{array}$ & $\begin{array}{l}34(79.1) \\
8(18.6) \\
1(2.3)\end{array}$ & $\begin{array}{l}148(86.0) \\
20(11.6) \\
4(2.3)\end{array}$ & 0.476 \\
\hline LVSI, n [\%] & $36(83.7)$ & $94(54.7)$ & 0.001 \\
\hline $\begin{array}{l}\text { Lymph node involvement, } \\
\mathrm{n}[\%]\end{array}$ & $4(57.1)$ & $16(44.4)$ & 0.538 \\
\hline
\end{tabular}

DFS — disease-free survival; LVSI — lymphovascular space invasion; MCV - mid-corpuscular volume; OS - overall survival 


\begin{tabular}{|c|c|c|c|}
\hline & Cases (43) & Controls (172) & $\mathbf{P}$ \\
\hline $\begin{array}{l}\text { Primary therapy, } \mathbf{n}[\%] \\
\text { Concurrent chemoradiotherapy } \\
\text { Surgery + adjuvant chemoradiotherapy } \\
\text { Radiotherapy } \\
\text { Surgery + adjuvant radiotherapy } \\
\text { Chemotherapy }\end{array}$ & $\begin{array}{l}17(39.5) \\
7(16.3) \\
17(39.5) \\
1(2.3) \\
1(2.3)\end{array}$ & $\begin{array}{l}106(61.6) \\
24(14.0) \\
18(10.5) \\
24(14.0) \\
0(0)\end{array}$ & 0.001 \\
\hline $\begin{array}{l}\text { Surgery, } \mathbf{n} \text { [\%] } \\
\text { Type } 1 \text { hysterectomy + BSO } \\
\text { Type } 2 \text { hysterectomy + BSO +PPLND } \\
\text { Type } 3 \text { hysterectomy + BSO + PPLND } \\
\text { PPLND }\end{array}$ & $\begin{array}{l}1(12.5) \\
1(12.5) \\
5(62.5) \\
1(12.5)\end{array}$ & $\begin{array}{l}12(25.0) \\
2(4.1) \\
32(66.6) \\
2(4.1)\end{array}$ & 0.580 \\
\hline $\begin{array}{l}\text { Type of chemotherapy: CCRT, } \mathbf{n} \text { [\%] } \\
\text { Cisplatin } \\
\text { Cisplatin + 5-fluorouracil } \\
\text { Cisplatin + carboplatin } \\
\text { Cisplatin + ifosfamide + paclitaxel }\end{array}$ & $\begin{array}{l}13(76.4) \\
1(5.8) \\
2(11.6) \\
1(5.8)\end{array}$ & $\begin{array}{l}98(92.5) \\
0(0) \\
6(5.7) \\
2(1.9)\end{array}$ & 0.048 \\
\hline Number of cycles & $2-6$ & $2-7$ & 0.219 \\
\hline $\begin{array}{l}\text { Type of chemotherapy: adjuvant CT, n [\%] } \\
\text { Cisplatin } \\
\text { Cisplatin + 5-fluorouracil } \\
\text { Carboplatin + paclitaxel }\end{array}$ & $\begin{array}{l}5(71.4) \\
1(14.3) \\
1(14.3)\end{array}$ & $\begin{array}{l}22(91.7) \\
0(0) \\
2(8.3)\end{array}$ & 0.144 \\
\hline Number of cycles & $6-7$ & $3-7$ & 0.002 \\
\hline $\begin{array}{l}\text { Primary radiotherapy } \\
\text { Internal radiotherapy dose range, Gy } \\
\text { External radiotherapy dose range, Gy }\end{array}$ & $\begin{array}{l}5-9 \\
45-64.8\end{array}$ & $\begin{array}{l}4-9 \\
36-61\end{array}$ & $\begin{array}{l}0.464 \\
0.147\end{array}$ \\
\hline $\begin{array}{l}\text { Adjuvant radiotherapy } \\
\text { Internal radiotherapy dose range, Gy } \\
\text { External radiotherapy dose range, Gy }\end{array}$ & $\begin{array}{l}5-9.25 \\
30.6-54\end{array}$ & $\begin{array}{l}5-9 \\
45-59\end{array}$ & $\begin{array}{l}0.240 \\
0.084\end{array}$ \\
\hline
\end{tabular}

BSO - bilateral salpingo-oophorectomy; CCRT — concurrent chemoradiotherapy; CT — chemotherapy; PPLND — pelvic para-aortic lymphadenectomy

recurrence treatment, the mean survival time after recurrence was $17.8 \pm 21.7$ months in CT group, $100.0 \pm 63.4$ months in surgery plus CT group and $21.0 \pm 23.6$ months in RT group $(p<0.001)$. In surgery plus CT group, survival time after recurrence was $24,72,144$ and 160 months. In RT group, survival time after recurrence was 4,11 and 48 months. Two of the surgically treated patients (50.0\%) underwent metastasectomy, and the other two (50.0\%) underwent lobectomy. Three (75.0\%) of the patients who underwent post-surgical CT received carboplatin + paclitaxel (6 cycles) and one (25.0\%) received cisplatin + paclitaxel + ifosfamide (4 cycles). Of the patients who underwent CT only, 11 (31.4\%) received carboplatin + paclitaxel (3-6 cycles), 8 (22.9\%) received carboplatin + ifosfamide (2-6 cycles), 7 (20.0\%) received cisplatin + ifosfamide (2-6 cycles), 4 (11.4\%) received carboplatin + 5-fluorouracil (3-6 cycles), and 4 (11.4\%) received carboplatin + cyclophosphamide (4-6 cycles). Patients receiving radiotherapy received $30-42$ Gy doses.

After detection of IPM, the 1-, 2-, and 5-year survival rates were $31.3,26.5$, and $15.9 \%$, respectively. The median survival time after metastasis detection was 12 months (range 2-160 months).
Risk factors for IPM were assessed by multivariate and univariate logistic regression analyses (Tab. 3). The presence of LVSI and a mid-corpuscular volume (MCV) $<80 \mathrm{fL}$ were statistically significant prognostic factors for IPM development in UCC patients according to univariate regression analyses, and the presence of LVSI, a hemoglobin level $<12 \mathrm{~g} / \mathrm{dL}$, and an $\mathrm{MCV}<80 \mathrm{fL}$ were statistically significant according to the multivariate regression analyses. We were unable to assess the role of lymph node status (involvement or reactive) as a prognostic factor in the development of IPM, because only seven patients (16.2\%) in the case group underwent lymph node dissection.

The factors affecting survival after IPM in UCC are listed in Table 4. Postmenopausal status was a significant factor according to the univariate analyses, and a DFS $\geq 12$ months was significant according to the multivariate analyses.

\section{DISCUSSION}

In this case-control study, we evaluated UCC patients with IPM. Risk factors were compared between the case and control groups. Previous studies in the literature have investigated pulmonary metastases [1, 4, 6-10]; however, 
Table 3. Odds ratios from univariate and multivariate analyses using the logistic regression model, with isolated pulmonary metastasis as the dependent variable

\begin{tabular}{|l|l|l|l|l|l|l|l|}
\hline & \multicolumn{3}{l|}{ Univariate analysis } & \multicolumn{3}{l|}{ Multivariate analysis } \\
\hline & OR & $\mathbf{9 5 \%} \mathbf{C l}$ & $\mathbf{P}$ & $\mathbf{O R}$ & $\mathbf{9 5 \%} \mathbf{C I}$ & $\mathbf{P}$ \\
\hline LVSI & 4.2 & $1.8-10.1$ & 0.001 & 4.6 & $1.6-13.0$ & 0.004 \\
\hline Hemoglobin $(<12 \mathrm{~g} / \mathrm{dL})$ & 0.7 & $0.3-1.4$ & 0.341 & 8.4 & $2.2-33.3$ & 0.002 \\
\hline MCV $(<80 \mathrm{fL})$ & 3.7 & $1.7-7.6$ & 0.001 & 21.0 & $5.3-82.4$ & 0.001 \\
\hline Postmenopausal & 1.8 & $0.8-4.0$ & 0.141 & 1.6 & $0.5-4.6$ & 0.359 \\
\hline Tumor size $(\geq 4 \mathrm{~cm})$ & 1.1 & $0.4-2.7$ & 0.735 & 1.3 & $0.4-4.4$ & 0.586 \\
\hline Hydronephrosis & 0.7 & $0.2-2.5$ & 0.601 & 0.5 & $0.1-2.1$ & 0.349 \\
\hline Non-SCC histological type & 1.6 & $0.6-3.8$ & 0.260 & 2.2 & $0.7-6.6$ & 0.130 \\
\hline
\end{tabular}

$\mathrm{Cl}$ - confidence interval; LVSI — lymphovascular space invasion; OR — odds ratio; SCC — squamous cell carcinoma

Table 4. Assessment of prognostic factors affecting survival time after metastasis

\begin{tabular}{|l|l|l|l|l|l|l|}
\hline & \multicolumn{2}{l|}{ Univariate analysis } & \multicolumn{3}{l|}{ Multivariate analysis } \\
\hline & HR & $\mathbf{9 5 \%} \mathbf{C l}$ & $\mathbf{P}$ & HR & $\mathbf{9 5 \%} \mathbf{C l}$ & $\mathbf{P}$ \\
\hline LVSI & 0 & - & 0.630 & 0.5 & $0.1-1.9$ & 0.375 \\
\hline Hemoglobin $(<12 \mathrm{~g} / \mathrm{dL})$ & 0.9 & $0.1-4.6$ & 0.924 & 0.6 & $0.2-1.7$ & 0.404 \\
\hline MCV $(<80 \mathrm{fL})$ & 0.5 & $0.1-2.8$ & 0.465 & 1.1 & $0.4-3.2$ & 0.726 \\
\hline Postmenopausal & 7.2 & $1.1-19.4$ & 0.022 & 0.3 & $0.1-1.4$ & 0.167 \\
\hline Tumor size $(\geq 4 \mathrm{~cm})$ & 0.5 & $0.1-8.0$ & 0.521 & 2.0 & $0.4-8.6$ & 0.323 \\
\hline Hydronephrosis & 0.7 & $0.1-5.1$ & 0.760 & 0.4 & $0.1-2.9$ & 0.410 \\
\hline Non-SCC histological type & 1.0 & $0.1-8.2$ & 0.984 & 0.6 & $0.2-1.8$ & 0.444 \\
\hline DFS ( $\geq 12$ months) & 0 & - & 0.424 & 2.9 & $1.1-7.9$ & 0.029 \\
\hline Number of lesions (multiple) & 1.7 & $0.3-9.1$ & 0.422 & 4.5 & $0.9-22.6$ & 0.065 \\
\hline
\end{tabular}

$\mathrm{Cl}$ — confidence interval; DFS — disease-free survival; HR — hazard ratio; LVSI — lymphovascular space invasion; MCV — mid-corpuscular volume; SCC — squamous cell carcinoma

to our knowledge, this is the first study to investigate risk factors for the development of IPM and factors affecting survival after IPM.

The rate of development of pulmonary metastases in UCC was $4.1-6.1 \%[8,9]$. The rates of pulmonary metastases were $3.2-4.2 \%$ in stage I, $5.0-13.0 \%$ in stage II, $7.4-9.4 \%$ in stage III, and $20.9-57.0 \%$ in stage IV disease [4, 9]. Pulmonary metastasis was seen in $83.9-96.0 \%$ of patients during the first 2 years after UCC diagnosis [9]. The mean duration of pulmonary metastases was $12-13$ months $[1,10]$. In our study, when the IPM incidence was $4.8 \%$, the mean detection time was 24.0 months (range 1-96 months) after UCC diagnosis. Of the IPM patients, $79.1 \%$ had squamous cell carcinoma (SCC), $18.6 \%$ adenocarcinoma, and $2.3 \%$ adenosquamous cancer. Within the IPM group, the rates of diagnosis of stage IB, stage IIA, stage IIIA, stage IIIB, and stage IVB were $2.9 \%, 1.6 \%, 6.0 \%$, $3.4 \%, 10.0 \%$, and $50.0 \%$, respectively.

Risk factors for pulmonary metastasis, which is the most common site of hematogenous metastasis, have been investigated in previous studies [3-5]. Those studies identi- fied pelvic lymph node involvement, diagnosis of non-SCC, and tumor size $>4 \mathrm{~cm}$ as risk factors for the development of pulmonary metastases in UCC patients $[9,11]$. In our cohort, the presence of LVSI (OR 4.6, 95\% Cl 1.6-13.0), a hemoglobin level $<12 \mathrm{~g} / \mathrm{dL}$ (OR 8.4, 95\% Cl 2.2-33.3), and an $\mathrm{MCV}<80 \mathrm{fL}$ (OR 21.0, 95\% Cl 5.3-82.4) were statistically significant prognostic factors, according to the multivariate regression analysis. The presence of LVSI (OR 4.2, 95\% $\mathrm{Cl} 1.8-10.1)$ and an MCV < $80 \mathrm{fL}(\mathrm{OR} 3.7,95 \% \mathrm{Cl} 1.7-7.6)$ were statistically significant prognostic factors according to univariate regression analysis for hematogenously developed IPM. Although LVSI was previously investigated as a risk factor for pulmonary metastasis, MCV has not been investigated in hematological metastasis previously; an $\mathrm{MCV}<80 \mathrm{fL}$ was found to be a risk factor in our study. Notably, menopausal status, tumor size, hydronephrosis, and non-SCC histological type, which have been previously presented as risk factors for several types of metastases, were not identified as statistically significant risk factors for IPM development in our study. 
Histological type (non-SCC), age ( $<60$ years), solitary pulmonary metastasis, tumor size, presence of lymph node metastases, and metastatic lesions have been reported as prognostic factors affecting survival after metastasis $[1,12,13]$. In our study, postmenopausal status (OR 7.2, 95\% Cl 1.1-19.4) was a risk factor for conditions affecting the post-recurrence survival time according to univariate regression analysis, and a DFS $\geq 12$ months (OR 2.9, 95\% Cl 1.1-7.9) was a statistically significant risk factor according to multivariate regression analysis.

The median survival after lung metastasis was 18 months, whereas the 2- and 5-year survival rates were $37.7 \%$ and $7.5 \%$, respectively $[3,13]$. Similarly, in our cohort, the 1-, 2-, and 5 -year survival rates after detection of IPM were $31.3 \%$, $26.5 \%$, and $15.9 \%$, respectively. In contrast, the median survival time after metastasis detection was 12.0 months (range 2-3160 months). The long survival time after metastasis may be due to isolated metastases.

Surgery combined with CT may provide a better prognosis for single, solitary pulmonary metastatic tumors [14]. The survival rate of patients with pulmonary metastasectomy was reported to be higher than that of patients receiving CT only; however, the difference was not statistically significant [6]. Following the necessary criteria for the selection of cases for surgical removal of recurrent pulmonary tumors is recommended, with the expectation of a 30\% 5-year survival rate $[7,9]$. Survival after complete metastasectomy was $36 \%$ at 5 years, $26 \%$ at 10 years, and $22 \%$ at 15 years (median 35 months), whereas that after incomplete resection was $13 \%$ at 5 years and $7 \%$ at 10 years (median 15 months) [7]. These outcomes indicate that metastasectomy is potentially curative [7]. The following are prerequisites for the application of pulmonary metastasectomy: the patient is at low risk for surgical intervention, the primary malignancy is controlled or controllable, there is no evidence of metastatic disease elsewhere, and complete resection of pulmonary metastases is possible [7]. Preferred conditions include the absence of hilar and mediastinal lymph node metastasis, fewer than four pulmonary lesions, a long disease-free interval, metastatic lesions no larger than $3 \mathrm{~cm}$ in diameter, and no elevation of serum tumor marker levels [7]. The response rate to platinum-based CT was $67.7 \%$, with a median survival of 8.3 months [8]. In our study, CT was usually the only treatment performed for metastasis (81.4\%). For the treatment of metastasis, the surgical approach was performed in only four patients (9.4\%). Experience with the surgical treatment of patients with IPM is lacking at our hospital. One reason for the low number of surgical treatments was the presence of multiple lesions in $81.4 \%$ of patients; another reason is that patients did not show a preference for surgical treatment when it was offered, due to the complications with surgical treatment and the cure rate after treatment. Accompanying comorbidities (diabetes, hypertension, asthma, etc.), which are impediments to surgery or cause an increased rate of complications, with an advanced average age of $58.9 \pm 10.8$ are other possible reasons. According to recurrence treatment, the mean survival time after recurrence was $17.8 \pm 21.7$ in CT group, $100.0 \pm 63.4$ in surgery plus CT group and $21.0 \pm 23.6$ months in RT group $(p<0.001)$. In surgery plus CT group, survival time after recurrence was 24, 72, 144 and 160 months. The significant difference in survival times between treatment groups may be due to patients with surgery are cases with solitary lesions. Therefore, patients who are eligible for surgical treatment (metastasectomy or lobectomy) are very fortunate in terms of survival.

The strengths of our study lie in the similarities in demographic characteristics among the study population, the availability of good follow-up data, and treatment at a single institution by the same gynecology and oncology teams. However, some limitations are worth mentioning. First, it was a retrospective analysis of UCC patients. Because of the retrospective nature of the study, the effects of other possible confounding factors, such as selection and recall bias, on our results cannot be ruled out. Second, although the patients in the control group were selected randomly to prevent bias, there were still differences within and between the groups with regard to surgery and treatment types. Third, we are aware that the lack of a surgery-alone treatment arm among the patients with recurrence is a major limitation of our study; this prevented us from comparing surgery with medical treatment (such as CT, $\mathrm{RT}$, and (RT). This situation depended not only on the lack of surgical experience but also on patient preference. Fourth, the small number of patients and different treatment regimens used over a period of 15 years are additional limiting factors that may potentially affect the comparisons negatively.

In conclusion, IPM typically develops within the first 3 years after the diagnosis of UCC, and survival is generally poor. An MCV < $80 \mathrm{fL}$ and the presence of LVSI are significant risk factors for IPM development. Effective treatment algorithms should be established to increase the survival of UCC patients diagnosed with IPM.

\section{Conflict of interests}

The authors report no conflicts of interest.

\section{REFERENCES}

1. Ki EY, Lee KHo, Park JS, et al. A Clinicopathological Review of Pulmonary Metastasis from Uterine Cervical Cancer. Cancer Res Treat. 2016; 48(1): 266-272, doi: 10.4143/crt.2014.206, indexed in Pubmed: 25715766.

2. Ries LAG, Harkins D, et al. SEER Cancer Statistics Review, 1975 to 2003. National Cancer Institute, Bethesda. 2006.

3. Li H, Wu X, Cheng Xi. Advances in diagnosis and treatment of metastatic cervical cancer. Journal of Gynecologic Oncology. 2016; 27(4), doi: 10.3802/jgo.2016.27.e43.

4. Tellis CJ, Beechler CR. Pulmonary metastasis of carcinoma of the cervix: a retrospective study. Cancer. 1982; 49(8): 1705-1709, indexed in Pubmed: 7066870.

5. Kanab R, El M'rabet F, Ameuraoui T, et al. [Squamous cell carcinoma of the cervix relapsing as an isolated pulmonary metastasis: report 
of a case and review of literature]. Pan Afr Med J. 2015; 22: 369, doi: 10.11604/pamj.2015.22.369.7217, indexed in Pubmed: 27022429.

6. Adachi M, Mizuno M, Mitsui $\mathrm{H}$, et al. The prognostic impact of pulmonary metastasectomy in recurrent gynecologic cancers: a retrospective single-institution study. Nagoya J Med Sci. 2015; 77(3): 363-372, indexed in Pubmed: 26412882

7. Yano T, Shoji F, Maehara Y. Current status of pulmonary metastasectomy from primary epithelial tumors. Surg Today. 2009; 39(2): 91-97, doi: 10.1007/s00595-008-3820-9, indexed in Pubmed: 19198984.

8. Barter JF, Soong SJ, Hatch KD, et al. Diagnosis and treatment of pulmonary metastases from cervical carcinoma. Gynecol Oncol. 1990; 38(3): 347-351, indexed in Pubmed: 2227546.

9. Imachi M, Tsukamoto N, Matsuyama T, et al. Pulmonary metastasis from carcinoma of the uterine cervix. Gynecologic Oncology. 1989; 33(2): 189-192, doi: 10.1016/0090-8258(89)90549-0.
10. Shu $T$, Bai $P$, Zhang $R$, et al. [Clinical analysis and prognostic factors in 106 patients with stage la-llb cervical cancer with pulmonary metastasis]. Zhonghua Zhong Liu Za Zhi. 2014; 36(9): 703-707, indexed in Pubmed: 25564063.

11. Zheng A, Chen Y, Fang J, et al. Clinicopathologic characteristics and risk factors for lung metastasis after radical hysterectomy in early-stage cervical cancer. 2015; 50(3): 204-9.

12. Yamamoto $\mathrm{K}$, Yoshikawa $\mathrm{H}$, Shiromizu K, et al. Pulmonary metastasectomy for uterine cervical cancer: a multivariate analysis. Ann Thorac Surg. 2004; 77(4): 1179-1182, doi: 10.1016/j.athoracsur.2003.06.023, indexed in Pubmed: 15063230.

13. Shiromizu K, Kasamatsu T, Takahashi M, et al. A clinicopathological study of postoperative pulmonary metastasis of uterine cervica carcinomas. J Obstet Gynaecol Res. 1999; 25(4): 245-249, indexed in Pubmed: 10540526. 